\title{
Potential impact of global warming on river runoff coming to Jor reservoir, Malaysia by integration of LARS-WG with artificial neural networks
}

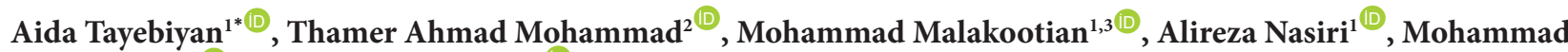 \\ Reza Heidari $^{1}{ }^{\mathbb{D}}$, Ghazal Yazdanpanah $^{10}$ \\ ${ }^{1}$ Environmental Health Engineering Research Center, Kerman University of Medical Sciences, Kerman, Iran \\ ${ }^{2}$ Department of Water Resources Engineering, College of Engineering, University of Baghdad, Baghdad, Iraq \\ ${ }^{3}$ Department of Environmental Health, School of Public Health, Kerman University of Medical Sciences, Kerman, Iran \\ ${ }^{4}$ Department of Environmental Health, School of Public Health, Bam University of Medical Sciences, Bam, Iran
}

\begin{abstract}
Background: Changes in temperature and precipitation pattern seriously affect the amount of river runoff coming into Dam Lake. These changes could influence the operating conditions of reservoir systems such as Jor hydropower reservoir system (Malaysia) with the total capacity of $150 \mathrm{MW}$. So, it is necessary to analyze the effect of changes in weather parameters on the river runoff and consequently, the hydropower production.

Methods: In this research, LARS-WG was used to downscale the weather parameters such as daily minimum temperature, maximum temperature, and precipitation based on one of the general circulation sub-model (HADCM3) under three emission scenarios, namely, A1B, A2, and B1 for the next 50 years. Then, the artificial neural network (ANN) was constructed, while rainfall and evapotranspiration were used as input data and river runoff as output data to discover the relationship between climate parameters and runoff at the present and in the future time.

Results: It was revealed that the monthly mean temperature will increase approximately between 0.3 $0.7^{\circ} \mathrm{C}$, while the mean monthly precipitation will vary from $-22 \%$ to $+22 \%$ in the next 50 years. These changes could shift the dry and wet seasons and consequently, change the river runoff volume. In most months, the results of models integration showed reductions in river runoff.

Conclusion: It can be concluded that the output of hydropower reservoir system is highly dependent on the river runoff. So, the impacts of climate changes should be considered by the reservoir operators/ managers to reduce these impacts and secure water supplies.

Keywords: Climate change, Neural Networks, Malaysia, Weather, Temperature

Citation: Tayebiyan A, Mohammad TA, Malakootian M, Nasiri A, Heidari MR, Yazdanpanah G. Potential impact of global warming on river runoff coming to Jor reservoir, Malaysia by integration of LARS-WG with artificial neural networks. Environmental Health Engineering and Management Journal 2019; 6(2): 139-149. doi: 10.15171/EHEM.2019.16.
\end{abstract}

Article History:

Received: 2 March 2019

Accepted: 14 April 2019

ePublished: 3 May 2019

\section{Introduction}

Climate changes affect temperature and precipitation patterns and consequently, influence water supply quantities. Due to limited adaptive capacities in dealing with extreme events, developing countries such as Malaysia are very vulnerable to climate changes (1). Due to the increasing water demand for industrial development and population growth, it is necessary to investigate the potential impacts of climate variability on water resources. These changes could influence the operating conditions of reservoir systems. Accordingly, one of the hydropower reservoir system, namely, Jor hydropower reservoir system with a total capacity of $150 \mathrm{MW}$ in Perak, Malaysia, was chosen as a case study.

Carnesale and Chameides declared that the main sources of recent climate changes and global warming are human activities, the industrial revolution, heating processes, especially burning fossil fuels for producing energy, deforestation, agricultural activities, and land use change (2). Researchers use observations and theoretical models to study past and future climatic conditions. The most reliable theoretical methods are general circulation models (GCMs), which are constructed based on the physical sciences. In order to plan future climate models 
in a large-scale (country-level), GCMs use observed data. Meanwhile, some techniques should be applied to convert the coarse resolution (country-level) of GCMs into the fine-resolution (regional-level) data of climate parameters. These techniques are called "downscaling" $(3,4)$. One of the most efficient, popular, and inexpensive downscaling methods is long ashton research stationweather generator (LARS-WG), which was expanded by Semenov and Barrow (5). In order to simulate climate parameters in a daily scale for both present and future conditions at a single site, LARS-WG was used (6-9). To calibrate the model, the observed daily weather data were analyzed. During calibration process, the observed weather data are analyzed using LARS-WG to determine the statistical characteristics and build a site-specific cumulative probability distribution (CPDs) for climate parameters such as minimum temperature (Tmin), maximum temperature (Tmax), precipitation, and solar radiation. Semi-experimental distributions like frequency distributions are used to analyze the dry/wet spell lengths, solar radiation, and daily precipitation of observed data. Then, for the Tmin and Tmax, Fourier series is applied. In the generation process, the site-specific file is used.

In order to generate optional time-series for synthetic weather parameters, random selection of values of the suitable distributions, the probability distributions of climatic variables are used. In order to estimate the probability distribution of dry/wet series of precipitation, Tmin, and Tmax in a daily scale, a semi-empirical distribution, namely, the CPD function is used (10). For more information about LARS-WG equations, it is recommended to refer to Semenov and Barrow (11), and Hassan et al (12). The above-mentioned climate parameters significantly affect the volume of water coming into a reservoir. The amount of water supply is a key factor in reservoir system operation. So, it is requisite to predict the amount of stream flow feeding a reservoir to improve the system operation and reduce the negative impacts of climate variation to simulate and predict the runoff, several methods such as stochastic model, conceptual model, and physically-based distributed model were used. Due to time- and space-based precipitation patterns, basin characteristics, the great number of parameters embedded in the model processing, and nonlinear compound relationships in the transformation of rainfall into runoff, these models were used in accompany with some estimations (13). In order to overcome these difficulties, black box models such as artificial neural networks (ANNs) have been attracted the attention of researchers. Kisi and Kerem Cigizoglu compared various ANN techniques to predict both short- and long-term daily stream flows (14). Nourani applied emotional ANN for modelling daily rainfall-runoff (15).

In this research, the climate of Jor reservoir, which is located in the Perak state of Malaysia, was investigated regarding the changes in precipitation, minimum temperature, and maximum temperature. In order to downscale the climate changes based on one of the GCMs sub-models (called HadCM3), the LARS-WG is used as a tool for generating weather statistically. The LARS-WG downscales the climate variables according to HadCM3 under three scenarios of emission, namely, A2, B1, and A1B. Afterwards, ANN is integrated to predict future stream flow coming into Jor reservoir. The procedure of each model will be explained in the next section.

\section{Materials and Methods \\ Downscaling by the LARS-WG Model \\ Model calibration}

The LARS-WG computes the statistical properties of each weather parameter according to the observed data. During the calibration process, a series of daily synthetic weather data were generated. A random number generator selects weather parameters from the site-specific CPDs and the properties of synthetic weather data were similar to those of observed data. The process of generation needs the number of years to be selected for simulation, like a random seeds that is controlling the stochastic weather generation. When the variables are different from a day to another, different random seeds create similar weather statistics (16). In the present study, the number of years and random seeds were taken as 50 and 541, respectively.

\section{Model validation}

During the calibration process, the statistical parameters were obtained. These parameters afterwards were used to create synthetic climate variables by means of statistical properties similar to the observed weather data. During the validation process, the statistical properties of the synthetic and observed weather data were compared to test the capabilities of LARS-WG for simulation of precipitation, Tmax, and Tmin, and also to determine whether it is appropriate for use or not. The LARS-WG facilitates this process using the Q-test option to determine how well it simulates the above-mentioned observed weather parameters. This downscaling tool applies some statistical tests such as the Kolmogorov-Smirnov (KS), student $t$ test, and F-test to determine if mean values, standard deviations, and distributions of the synthetic data significantly differ from the observed weather data.

\section{Synthetic weather data generation}

The LARS-WG generates synthetic weather data by synthesizing the statistical feature files, which were obtained in the calibration process from the observed weather data with a scenario file embedded data of precipitation changes, solar radiation, temperature variability, mean temperature, and wet/dry series duration. This tool thereafter creates daily weather parameters according to the emission scenarios simulated by GCMs sub-models, while monthly changes of each parameter are embedded in the scenarios (17). 


\section{Generation of climate scenarios}

A daily climate scenario can be generated by perturbing the parameters of distributions for a certain site with the predicted $\Delta$-changes, which are derived from regional or global climate models. The baseline parameters calculated from the observed dataset, can be adjusted using $\Delta$-changes based on each emission scenario for future period to create climate scenarios for a certain future period. Climate variables afterwards will be predicted by the GCM sub-model (HadCM3).

In the present research, three emission scenarios, namely, A1B, A2, and B1 were applied to predict the future climate parameters. These scenarios have different prospects for the future. $\mathrm{A} 1 \mathrm{~B}$ indicates a balanced socioeconomic and environmental development in the future; A2 assumes that the socioeconomic development remains the same till future; and B1 indicates that future development is very compatible with the environment (18). The predictions were done based on the HadCM3 model, proposed by many researchers $(19,20)$. UK meteorological office research centre proposed HadCM3 (21). Since this model does not require flux adjustments for producing a realistic scenario, using 360 days per year, where each month has 30 days with a spatial grid of $2.5^{\circ}$ latitude $\times 3.75^{\circ}$ longitude, it is considered as a unique model among GCMs models (22).

The whole process of generating weather parameters by the LARS-WG method is summarized in Figure 1.

\section{Artificial neural networks}

ANNs are information processing systems that mimic the human brain functions. In ANN structure, there are a number of processing elements called neurons. The neurons connect to each other by weights (23). The neurons are embedded in layers. The neurons in each layer are linked to the neurons in the adjacent layers. The strength of the connection between two neurons in adjacent layers is determined by the layers' weights.

The basic structure of ANN consists of three layers: input, hidden, and output layers. The input layer is the layer, where the data are imported into the network. In the hidden layer, the imported data are processed, and in the output layer, the output of ANN is generated. ANN models generally could be a 'feed forward' or 'feedback' network. Due to the nature of the problem, the feed forward network was chosen. In this type of network, the input layer data goes into the output layer only in the forward direction to specify the weight matrix and find the relationship between the input/output data. The most important stage in developing an ANN is the training stage. Based on the learning rules in the training stage, the network weights and biases should be adjusted, which is a problem. In order to solve this problem, back propagation learning rule is applied to train the network. Back propagation is a part of the gradient descent method. ANN processing system interconnects the neural computing elements based on the back propagation in a parallel manner. In the process of back propagation, the errors from the output layer elements and also the errors from the hidden layer elements are specified. Afterwards, until obtaining the minimum error between the target and computed outputs, the network weights are continuously adjusted and revised (24). Training pairs are chosen from the training set and based on the inputs used for training pairs, the network computes the outputs. Training pairs compare the network obtained results with the outputs. According to the ANN output, the weights add biases to all neurons, adjusted by a coefficient based on the difference between target and calculated output (errors), target and the derivation of the sigmoid function. For more information about ANN with back propagation training, it is recommended to refer to Fahlman (25). The back propagation ANN structure is illustrated in Figure 2.

\section{Model Development}

Here, an ANN is expanded to determine the rainfallrunoff relationship (Figure 3). To construct the model, three parameters in a daily scale were used such as rainfall, river discharge, and evapotranspiration. Rainfall data was collected from Empangan station, river discharge data was collected from Tenaga Nasional Berhad (TNB), and evapotranspiration was estimated using the HargreavesSamani (HS) equation. Only observed minimum and maximum temperatures were used by HS to estimate evapotranspiration. For more information about this equation, it is recommended to refer $(26,27)$.

$$
\text { ET0 }=0.0135 . \mathrm{K}_{\mathrm{Rs}} \cdot \mathrm{R}_{\mathrm{a}} \cdot\left(\mathrm{T}_{\max }-\mathrm{T}_{\min }\right)^{0.5}\left(\mathrm{~T}_{\mathrm{a}}+17.8\right)(1)
$$

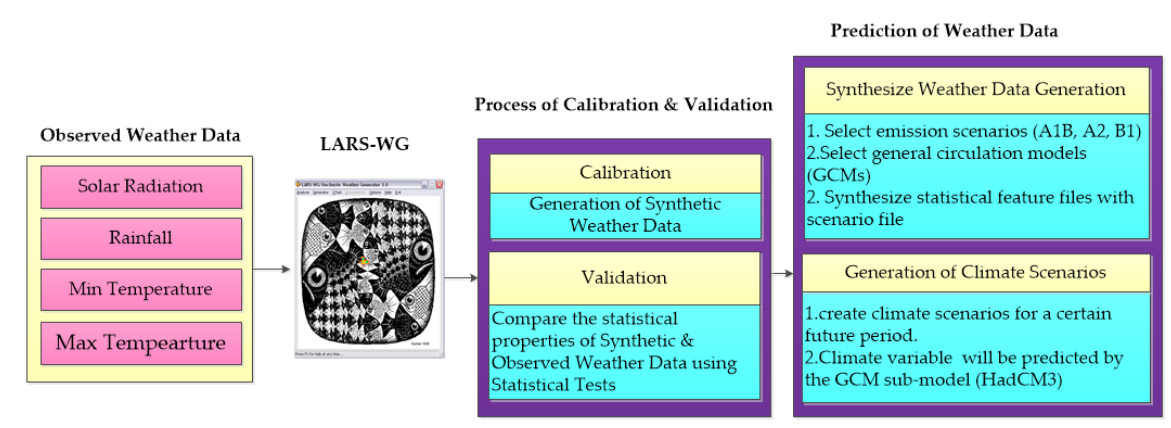

Figure 1. Process of downscaling using LARS-WG. 


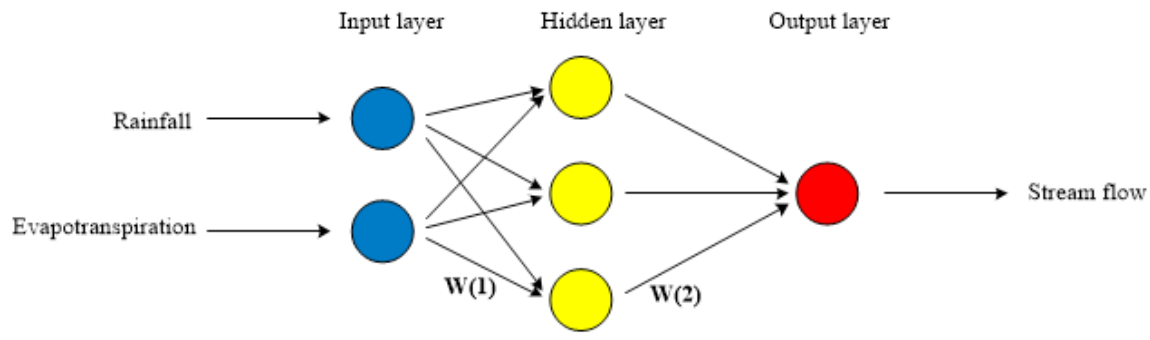

Figure 2. Schematic of back propagation ANN model.

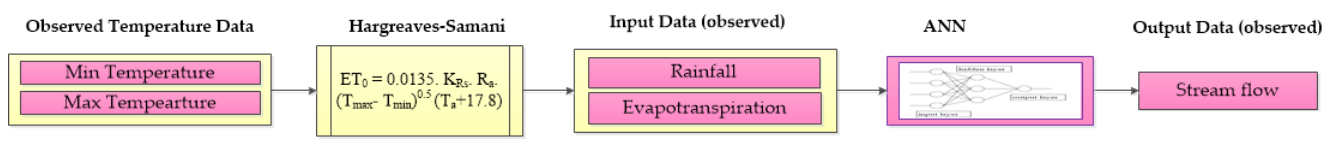

Figure 3. Procedure of ANN training as rainfall-runoff modelling.

Where ET0 is evapotranspiration ( $\mathrm{mm} /$ day), 0.0135 is a factor to convert American units to the international system of units, $\mathrm{K}_{\mathrm{Rs}}$ is the adjustment coefficient of radiation, commonly equal to $0.17(28), \mathrm{R}_{\mathrm{a}}$ is the extraterrestrial radiation $(\mathrm{mm} /$ day $)$, and $\mathrm{T}_{\min }, \mathrm{T}_{\max }$, and $\mathrm{T}_{\mathrm{a}}$ are the minimum, maximum, and average daily air temperature $\left({ }^{\circ} \mathrm{C}\right)$, respectively.

Moreover, the input layer consists of two parameters (evapotranspiration and rainfall), while the river discharge makes the output layer. The dataset was randomly divided into two subsets including the training set and testing set, while $70 \%$ of data were used for training and the rest (30\%) was applied as a testing set.

\section{Model Evaluation}

To assess the performance of the developed ANN model, four statistical measurements including Nash-Sutcliffe efficiency coefficient (E), correlation coefficient (r), root mean square error (RMSE), and mean bias error (MBE), were used (26). RMSE and MBE were used to evaluate the capability of the model for the prediction of data from a calibrated model. The other statistics ( $\mathrm{E}$ and $\mathrm{r}$ ) measure the difference between observed data and simulated data (27). These statistical criteria were calculated based on the following equations.

Nash-Sutcliffe efficiency coefficient (E)

$$
E=1-\frac{\sum_{i=1}^{n}\left(X_{o b s, i}-X_{\text {model }, i}\right)^{2}}{\sum_{i=1}^{n}\left(X_{o b s, i}-\overline{X_{o b s, i}}\right)^{2}}
$$

Correlation coefficient (r)

$$
r=\frac{\sum_{i=1}^{n}\left(X_{i}-\overline{X_{l}}\right) \cdot\left(Y_{i}-\bar{Y}_{l}\right)}{\sqrt{\sum_{i=1}^{n}\left(X_{i}-\bar{X}_{l}\right)^{2} \cdot\left(Y_{i}-\bar{Y}_{l}\right)^{2}}}
$$

Root Mean Square Error (RMSE)

$$
\text { RM) } M S=\sqrt{\frac{\sum_{i=1}^{n}\left(X_{o b s, i}-X_{\text {model }, i}\right)^{2}}{n}}
$$

Mean Bias Error (MBE)

$$
M B E=\frac{\sum_{i=1}^{n}\left(X_{\mathrm{model}, i}-X_{o b s, i}\right)}{n}
$$

Where, $X_{\text {model }, i}$ and $X_{o b s, i}$ represent simulated and observed values, respectively, $X_{o b s, i}$ shows the mean value of observed data, and $n$ is the number of samples. Moreover, $X_{i}$ and $Y_{i}$ are the input and output values of the ANN model, respectively. $\bar{X}_{l}$ and $\bar{Y}_{l}$ denote the mean values of input and output data, respectively.

\section{Models integration (LARS-WG with ANN)}

In the last stage, the future Min and Max temperature data (LARS-WG output) were used to estimate the future evapotranspiration using HS equation. The future evapotranspiration data and the generated rainfall data in the future (LARS-WG output) were imported to training ANN to predict the future stream flow coming into the reservoir. The integrated model of LARS-WG with ANN is presented in Figure 4.

Study area and data collection

In Figure 5, Jor reservoir is shown in the Perak state, Malaysia (17). This reservoir is a part of the Batang Padang hydroelectric project, which collects the water from 3 rivers, namely, Jor, Sekam, and Batang Padang River, and also the water of Sultan Yussuf Power Station. The collected water transfer to underground power station of Sultan Idris II through Menglang tunnel. Meanwhile, 


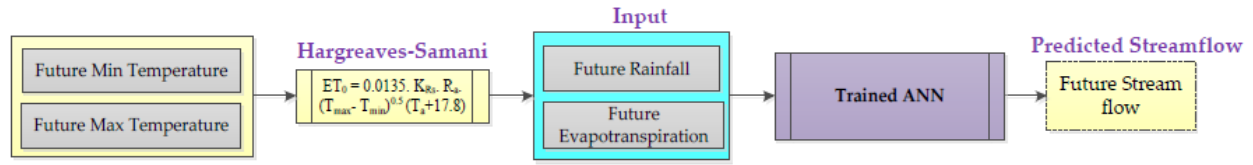

Figure 4. Integrated model of LARS-WG with ANN.

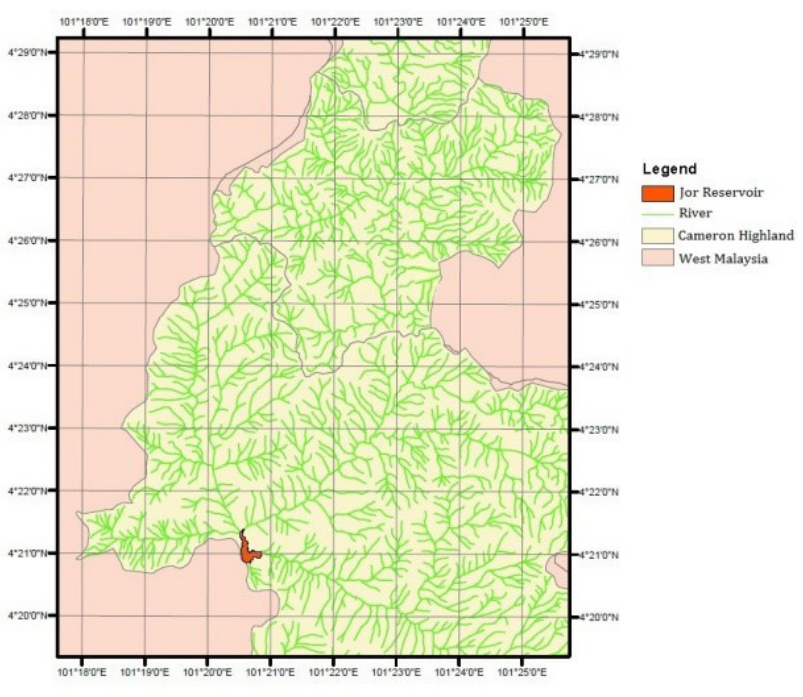

Figure 5. Jor Reservoir in the State of Perak, Malaysia.

changes in weather parameters such as temperature increase, significantly influence water availability and power output. So, prediction of future climate parameters at Jor Reservoir is of great importance. In order to provide the LARS-WG input, the weather data of the closet stations to the Jor reservoir were collected (Table 1).

\section{Results}

LARS-WG calibration and validation results

Before running LARS-WG for simulating and predicting future climate parameters, the performance of weather generator model should be validated for a considered site. The main function of weather generators is to generate climate parameters with statistical characteristics the same as the observed data. LARS-WG has a Q-test option to specify how well the model could simulate the observed characteristics. In this stage, the statistical characteristics of the observed data were compared with synthetic data. In order to specify if the standard deviations distributions, and mean values of the synthetic data are significantly different from the observed data, some statistical tests were applied.
Here, the observed data from 1984 to 2012 were used to validate the model. KS test was applied to determine the equality of the seasonal distributions in wet/dry series (W/D), daily maximum temperature distributions (D.Tem ${ }_{\text {Max }}$ ), daily minimum temperature distributions $\left(D \cdot \mathrm{Tem}_{\mathrm{Min}}\right.$ ), and daily rainfall distributions (D.Ra) between observed and synthetic data. The equality of monthly rainfall (M.Ra), monthly maximum temperature $\left(\mathrm{M} . \mathrm{Tem}_{\mathrm{Max}}\right)$, and monthly minimum temperature $\left({\mathrm{M} . T e \mathrm{M}_{\mathrm{Min}}}_{\mathrm{n}}\right)$ in an average were evaluated by t-test. Moreover, the equality of monthly variances for rainfall data (MV.Ra) was determined by the F-test.

The results are shown in Table 2, where the numbers represent how many tests was failed and have a significant difference at $P=0.05$, out of the total tests ( $4 \mathrm{dry} / 4$ wet seasonal scale or 12 monthly scale). A large number of tests showed a poor performance for the generation of synthetic data. The KS test output indicates that LARS-WG could perfectly simulate the distributions of (W/D), (D.Tem ${ }_{\text {Max }}$ ), $\left(D . \mathrm{Tem}_{\mathrm{Min}}\right)$, and (D.Ra). Since zero number reveals that there is no difference between synthetic and observed data distribution. Mean monthly minimum temperature $\left(\mathrm{M} . \mathrm{Tem}_{\mathrm{Min}}\right)$ and mean monthly maximum temperature (M. Tem ${ }_{\text {Max }}$ ) were found to be $2 / 12$, which means 2 out of 12 months has a significant difference $(P=0.05)$. These discrepancies were occurred on March (15.20 versus $15.30)$ and July (15.20 versus 15.30) for M.Tem ${ }_{\text {Min }}$, and on January (21.60 versus 21.90) and October (21.90 versus

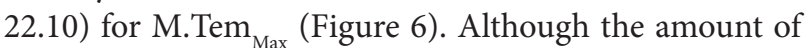
monthly observed and simulated data in the mentioned months are not equal but they are almost the same, which can be neglected compared to 10 months that LARSWG could completely simulate the equality of monthly mean minimum and maximum temperatures and match very well (with exact number in most months) with the observed historical data. It was found that LARS-WG is able to simulate the extreme temperature.

Moreover, the output results of monthly rainfall show that the model perfectly simulates the monthly mean rainfall ( 0 out of 12) compared to the monthly rainfall variance (4 out of 12 ) (Table 2 ). Monthly standard deviation and

Table 1. Weather data used as LARS-WG input

\begin{tabular}{|c|c|c|c|c|c|c|}
\hline Station & Climate parameters & Longitude & Latitude & Altitude & Range of data & Source \\
\hline Empangan Jor & Daily precipitation & $101^{\circ} 20^{\prime} \mathrm{E}$ & $4^{\circ} 20^{\prime} \mathrm{N}$ & 519.9 & $1984-2012$ & Tenaga Nasional Berhad \\
\hline $\begin{array}{l}\text { Cameron } \\
\text { Highland }\end{array}$ & $\begin{array}{l}\text { Daily min and max } \\
\text { temperature }\end{array}$ & $101^{\circ} 22^{\prime} \mathrm{E}$ & $4^{\circ} 28^{\prime} \mathrm{N}$ & 1545 & 1984-2012 & $\begin{array}{c}\text { Meteorological } \\
\text { Department }\end{array}$ \\
\hline
\end{tabular}


Table 2. Statistical results of comparison of the equality of observed and simulated data generated

\begin{tabular}{|c|c|c|c|c|c|c|c|c|}
\hline \multirow{2}{*}{ Site } & $W / D$ & D.Ra & D. Tem $_{\text {Max }}$ & D.Tem $_{\text {Min }}$ & M.Ra & M. Tem ${ }_{\text {Max }}$ & M.Tem $_{\text {Min }}$ & MV.Ra \\
\hline & \multicolumn{4}{|c|}{ KS test } & \multicolumn{3}{|c|}{ t-test } & F-test \\
\hline Ringlet & 0 & 0 & 0 & 0 & 0 & 2 & 2 & 4 \\
\hline Total tests & 8 & 12 & 12 & 12 & 12 & 12 & 12 & 12 \\
\hline
\end{tabular}

The seasonal distributions of wet and dry series (W/D), distributions of daily rainfall (D.Ra), daily maximum temperature (D.Tem ${ }_{\text {Max }}$ ), and daily minimum temperature (D.TemMin), monthly mean rainfall (M.Ra), monthly mean maximum temperature (M.Tem ${ }_{\text {Max }}$ ), monthly mean minimum temperature $\left(\mathrm{M} . \mathrm{Tem}_{\mathrm{Min}}\right)$, and monthly variances of rainfall (MV.Ra). The numbers in the table show how many tests were failed and showed significant differences at $\mathrm{P}=0.05$.

average of observed and simulated rainfall are presented in Figure 7. As shown in this figure, LARS-WG could perfectly simulate the mean monthly rainfall like the observed data. However, it could not simulate the monthly standard deviation of parameters like the monthly mean of the same parameters. In most statistical downscaling research, models struggle to capture the equal standard deviations and the output model was less than the standard deviation of observed data. Hashmi et al applied LARS-WG and SDSM downscaling models to evaluate these models for the prediction of future parameters in the Clutha watershed located in South Island, New Zealand. The output results showed that the downscaling models had difficulties to capture the standard deviation of observed rainfall (29).
Prediction of weather data based on the A1B, A2, and B1 scenarios

The average monthly observed minimum temperature (dashed line) and changes in M/Tmin compared to the observed data in 2011-2030 under the emission scenarios A1B, A2, and B1 (column charts), are shown in Figure $8 \mathrm{~A}$. As shown in this figure, due to global warming, Min temperature will increase in all months in the future. The above-mentioned scenarios show an increase in the minimum temperature about 0.3 to $0.7^{\circ} \mathrm{C}$ in the future. Scenarios follow a uniform shape, which shows a strong correlation and close agreement among GCM outputs. The results show that the highest discrepancy between observed and simulated data was obtained on March (+0.65) and April (+0.60), respectively, and the

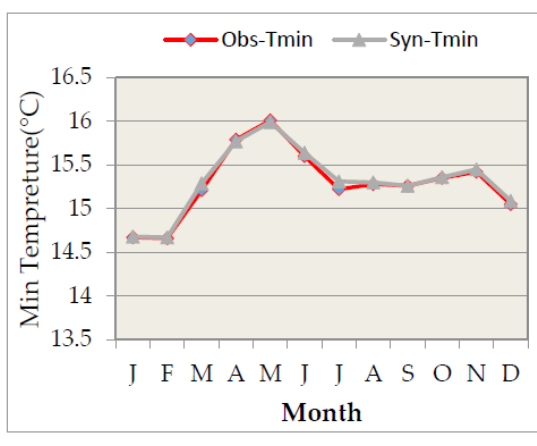

(A)

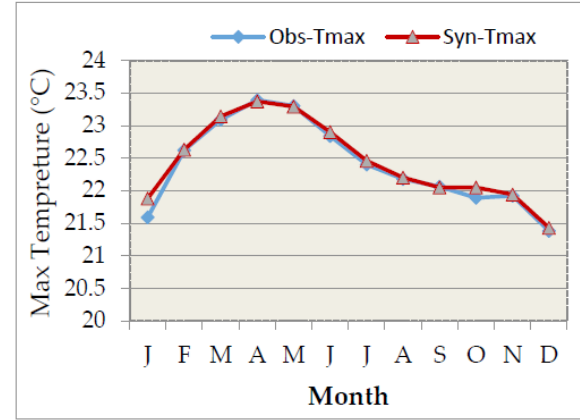

(B)

Figure 6. (A) Comparison of the monthly mean observed and simulated minimum temperature during 1984 to 2012 , (B) Comparison of the monthly mean observed and simulated maximum temperature during 1984 to 2012.

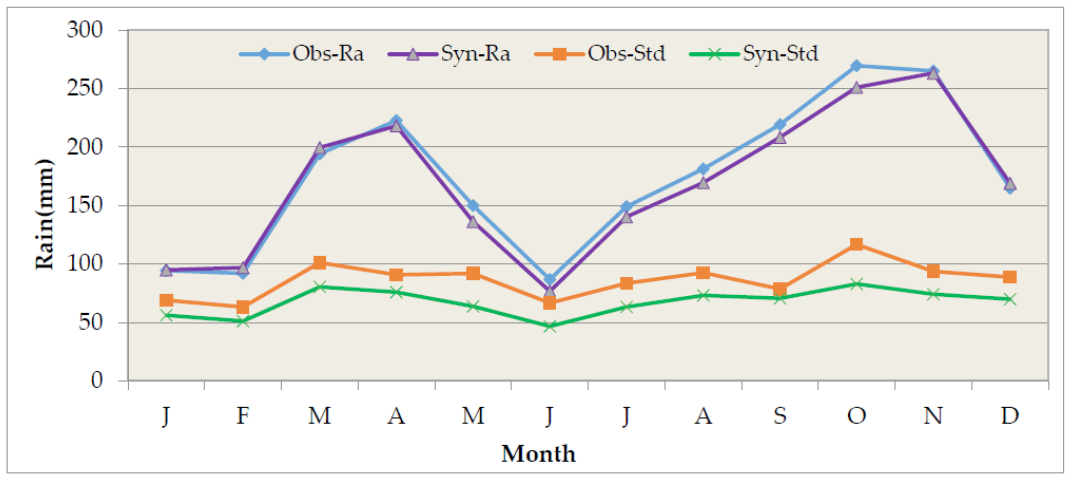

Figure 7. Comparison of the monthly mean and standard deviation of the observed and simulated rainfall. 
lowest increment was observed on September $(+0.43)$ by scenario A1B. Among the selected scenarios, A2, B1, and $\mathrm{A} 1 \mathrm{~B}$, respectively showed the trends of increment from the lowest to the highest difference.

The same procedure was applied for monthly maximum temperature and the results are represented in Figure $8 \mathrm{~B}$. The monthly maximum temperature will increase approximately between $0.3-0.7^{\circ} \mathrm{C}$ in $2011-2030$. The significant difference between baseline and future values occurs on January and March (about $0.7^{\circ} \mathrm{C}$ increase in temperature), and the lowest one will be occurred on September $(+0.4)$ by scenario A1B. In an overall, mean temperature will be increased in a whole year at Jor Dam Lake in the future. This increase happens because the area has undergone a very rapid urbanization, transportation, and buildings development. These developments have increased temperature in this area.

Monthly mean observed rainfall (dashed line) and changes in the monthly rainfall compared to the observe data (column charts) during 2011-2030 are shown in Figure 9. The increase or decrease in the total monthly rainfall are shown by positive and negative numbers, respectively. The greatest decrease in rainfall will occur on March with $-44.5 \mathrm{~mm}$ decrease by A1B and the highest decrease will occur on October by $58.36 \mathrm{~mm}$ by scenario A2. In an overall, differences between future and baseline rainfall in these months varied from $-20 \%$ to $+20 \%$. The amount of rainfall will decrease in most months, which could directly influence water supply and consequently, the output of power production.

ANN calibration and validation results

In this research, the dataset was categorized into two sets. The training set comprises $70 \%$ of the dataset and $30 \%$ of the data was used for testing set. Significant property of ANN is the number of neurons in the hidden layers, which should be selected to make an ANN. The best number was found to be 10 neurons by trials/errors. The proposed architecture was used to predict runoff for the main river feeding the Jor reservoir. Afterwards, the network was used for the prediction of future runoff coming to Jor reservoir. The input data of the network comprise of two components, including rainfall and evapotranspiration. The daily data of rainfall $(\mathrm{mm})$ were collected from the Empangan Jor station and the daily evapotranspiration data $(\mathrm{mm})$ were estimated using HS equation. Batang Padang stream flow made an output data of the model. Four statistical measurements were used to evaluate the network performance (Table 3). The Nash-Sutcliffe efficiency coefficient was used to assess the predictive power of hydrological models, which was obtained 0.94 in training set and 0.92 in the testing set. According to these results, the network has an appropriate power. A correlation coefficient is a measure to determine the

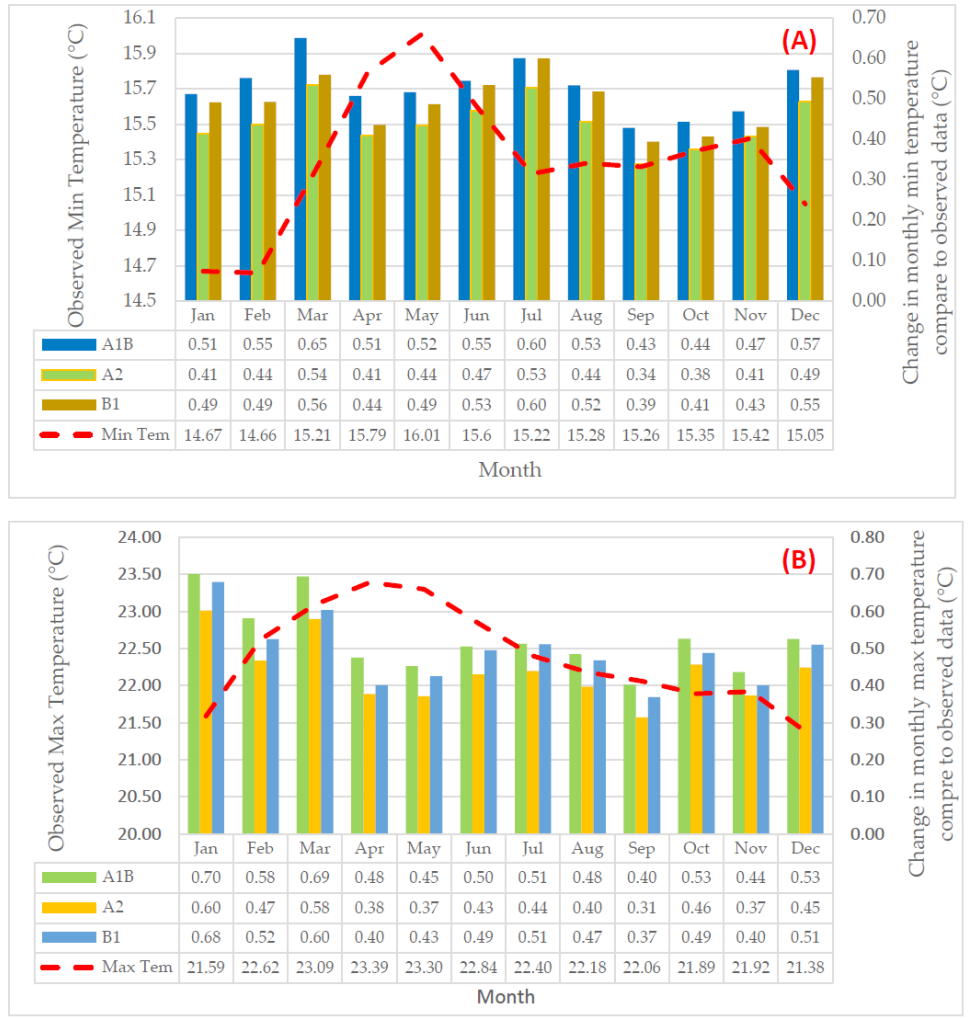

Figure 8. (A) Monthly mean observed Min temperature (dashed line), changes in the monthly Min temperature by A1B, A2, and B1 compared to the observed Min temperature $\left({ }^{\circ} \mathrm{C}\right),(B)$ Monthly mean observed Max temperature (dashed line), changes in the monthly Max temperature by $A 1 B$, A2, and B1 compared to the observed Max temperature $\left({ }^{\circ} \mathrm{C}\right)$. 


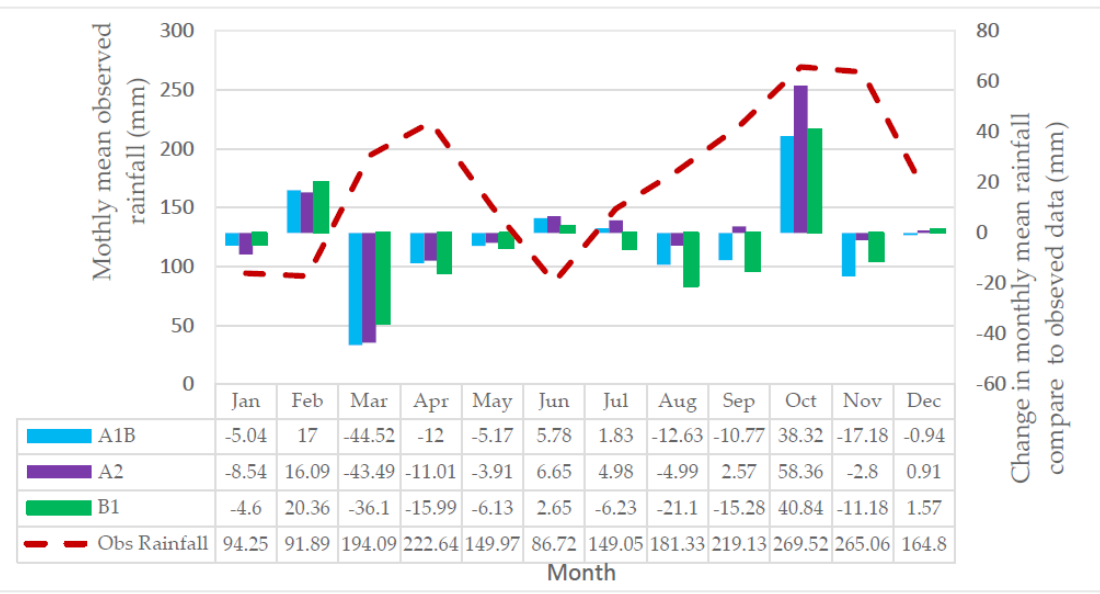

Figure 9. (Monthly mean observed rainfall (dashed line), changes in the monthly rainfall by $\mathrm{A} 1 \mathrm{~B}, \mathrm{~A} 2$, and $\mathrm{B} 1$ compared to the observed rainfall $\left({ }^{\circ} \mathrm{C}\right)$.

strength and direction of the relationship between two or more variables, which found to be 0.93 in training set and 0.96 in testing set. These results show that the ANN has highly empowered to determine the relationship between input and output data. RMSE and MBE were used to determine the differences between predicted values by the model and observed values. The results show the capability of ANN as a simulator and predictor.

Figure 10 shows the comparison of observed and simulated stream flow data ( $\mathrm{mm} /$ day) by the ANN. The Nash-Sutcliffe coefficient was found to be 0.94 in this model. This measurement indicates that the model has a good fit. The results show a quite strong fit between the observed and simulated data. The relationship between the observed stream flow $(\mathrm{X})$ and generated stream flow (Y) is found as follows.

$\mathrm{Y}=0.9964 \mathrm{X}+0.003(5)$

\section{Discussion}

In order to investigate the stream flow response to future climate scenarios, the outputs of LARS-WG based on the $\mathrm{A} 1 \mathrm{~B}, \mathrm{~A} 2$, and $\mathrm{B} 1$ emission scenarios were used. The minimum and maximum temperature results of scenarios were used to estimate the future evapotranspiration using HS equation. Afterwards, the daily evapotranspiration and rainfall of each scenario were imported to the trained ANN model to predict future stream flow based on the A1B, A2, and B1 scenarios. The results of monthly mean stream flow at present and based on the emission scenarios are shown in Figure 11. The results demonstrate that while the difference between the scenarios in each month are not significant, there are discrepancies between monthly mean stream flow in the future and present times. For example, it is clear that the amount of stream flow will decrease on January, March, September, and November. These decrements can be justified due to evapotranspiration increase and rainfall decrease in these months. Another research was also conducted in Malaysia to investigate the effects of climate changes on the stream flow for the Bernam river basin. They found that the trend of stream flow in the future is consistent with the future monthly changes in the rainfall and temperature patterns. The predicted increase in temperature could increase the daily evapotranspiration and interfere with the decrease in stream flow directly (30). Moreover, it seems that climate changes can not only influence the amount of stream flow, but also shift the peak flow from November to October and exchange dry month from February to January in the future. This variation directly affects water availability in the reservoir. As discussed earlier, the highest variation in temperature and the highest decrease in rainfall were obtained in March. These results are completely shown in Figure 11. It is evident that the amount of future stream flow on March will decrease from 5.05 to 4.85 $\mathrm{m}^{3} / \mathrm{s}$. It can be concluded that the amount of rainfall and evapotranspiration directly affect the future stream flow (31).

This study can be used by manager and operator of Jor reservoir (Malaysia) to modify and improve the reservoir operation based on the future stream flow. So, similar studies can be applied for the management of water

Table 3. Statistical evaluation measurements

\begin{tabular}{lcccc}
\hline Model Evaluation & Nash-Sutcliffe coefficient (E) & Correlation coefficient ( $\mathbf{r})$ & Root mean square error (RMSE) & Mean bias error (MBE) \\
\hline Training Set & 0.94 & 0.93 & 0.055 \\
Test Set & 0.92 & 0.96 & 0.050 \\
\hline
\end{tabular}




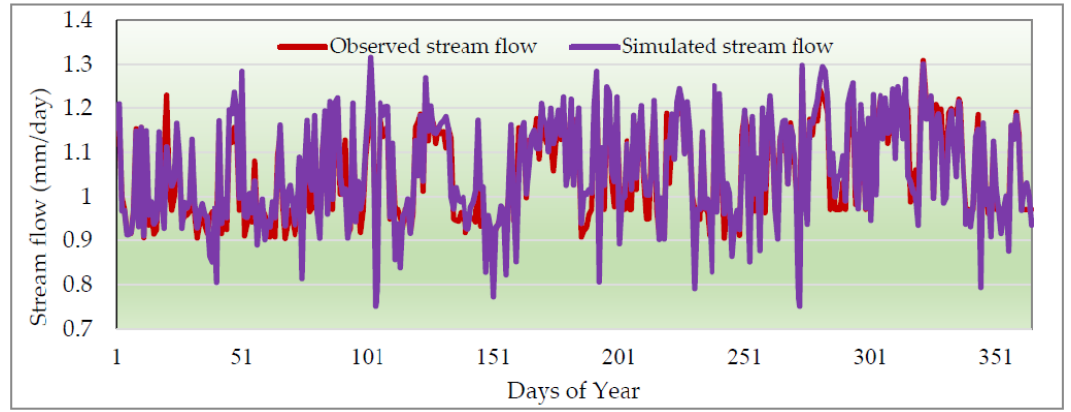

Figure 10. Comparison of the daily observed and simulated stream flow by the ANN for Batang Padang River.

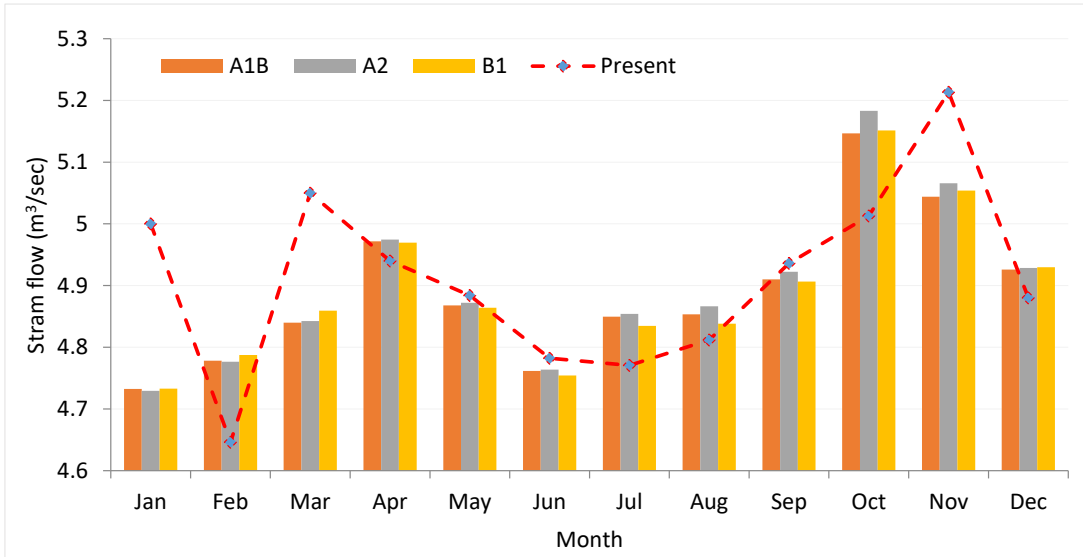

Figure 11. Comparison of the monthly mean Batang Padang stream flow at the present and in future time.

resources in other places in the world. It is recommended to use and evaluate the other weather generator for downscaling the climate data in the future. In addition, due to lack of access to land use and soil type maps in this area, only evapotranspiration and rainfall were used to predict the stream flow. So, it is proposed to use more data for the prediction of stream flow.

\section{Conclusion}

In this research, an integrated model of LARS-WG and ANN was used to predict the future stream flow feeding the Jor Dam Lake. Jor reservoir is a part of the Batang Padang Hydropower project with the entire capacity of 150 MW. Since the amount of water availability directly affects the power production output, therefore, it is crucial to predict the water coming to the reservoir to advise and help managers improve the reservoir system operation policy in order to reduce the negative effects of global warming and climate variability. Accordingly, one of the most promising downscaling techniques (LARS-WG) was used to simulate the observed weather parameters from 1984-2012. Afterwards, one of the sub models in GCM (HADCM3) was used to predict the climate parameters in the next 50 years under three emission scenarios, A1B, A2, and $\mathrm{B} 1$. The output results demonstrate that an average monthly temperature will increase approximately between $0.3-0.7^{\circ} \mathrm{C}$ and mean monthly precipitation will change from $-22 \%$ to $+22 \%$ in the next 50 years. Increasing the temperature directly affects the amount of precipitation and shifts the dry and wet months. The ANN, thereafter, was constructed to simulate and predict the effects of climate changes on river runoff. The results demonstrated that the ANNs models are effective and applicable, especially in problems, which the properties of the processes are difficult to describe by the physical equations. The present research indicates the potential of ANN for simulating the nonlinear hydrologic behaviour of watersheds. The output of ANN showed that the amount of stream flow will decrease in most months. Since river runoff is the key factor in hydropower production output, the prediction of stream flow could help managers improve and revise the reservoir system operation policy in securing the water availability and mitigate the negatives effects of climate variability.

\section{Acknowledgments}

The authors would like to thank the TNB and Meteorological Department, Malaysia, for providing all required data. 


\section{Ethical issues}

The authors hereby certify that all data collected during the research are as expressed in the manuscript, and no data from the study has been or will be published elsewhere separately.

\section{Competing interests}

The authors have declared that they have no conflict of interests.

\section{Authors' contributions}

All authors contributed in data collection, analysis, and interpretation. All authors reviewed, refined, and approved the manuscript.

\section{References}

1. Zarghami M, Abdi A, Babaeian I, Hassanzadeh Y, Kanani R. Impacts of climate change on runoffs in East Azerbaijan, Iran. Glob Planet Change 2011; 78(3-3): 137-46. doi: 10.1016/j.gloplacha.2011.06.003.

2. National Academy of Sciences. America's Climate Choices. [cited 2 Feb 2019]; Available from: https://www.nap.edu/ resource/12781/ACC-final-brief.pdf.

3. Giorgi F, Gutowski WJ Jr. Regional dynamical downscaling and the CORDEX initiative. Annu Rev Environ Resour 2015; 40(1): 467-90. doi: 10.1146/annurevenviron-102014-021217.

4. Knutson TR, Sirutis JJ, Zhao M, Tuleya RE, Bender M, Vecchi GA, et al. Global projections of intense tropical cyclone activity for the late twenty-first century from dynamical downscaling of CMIP5/RCP4. 5 scenarios. J Clim 2015; 28(18): 7203-24. doi: 10.1175/jcli-d-15-0129.1.

5. Semenov MA, Barrow EM. Use of a stochastic weather generator in the development of climate change scenarios. Clim Change 1997; 35(4): 397-414. doi: 10.1023/a:1005342632279.

6. Dehghan Z, Fathian F, Eslamian S. Comparative assessment of SDSM, IDW and LARS-WG models for simulation and downscaling of temperature and precipitation. Journal of Water and Soil 2017; 29(5): 1376-90. doi: 10.22067/jsw. v29i5.32589. [In Persian].

7. Sarkar J, Chicholikar JR, Rathore LS. Predicting future changes in temperature and precipitation in arid climate of Kutch, Gujarat: analyses based on LARS-WG model. Curr Sci 2015; 109(11): 2084-93. doi: 10.18520/v109/111/20842093.

8. Kishiwa P, Nobert J, Kongo V, Ndomba P. Assessment of impacts of climate change on surface water availability using coupled SWAT and WEAP models: case of upper Pangani River Basin, Tanzania. Proceedings of the International Association of Hydrological Sciences 2018; 378: 23-7. doi: 10.5194/piahs-378-23-2018.

9. Khalili N, Davary K, Alizadeh A, Ansari H, Rezaee Pazhand H, Kafi M, et al. Evaluation of the performance of ClimGen and LARS-WG models in generating rainfall and temperature time series in rainfed research station of Sisab, Northern Khorasan. Journal of Water and Soil 2016; 30(1): 322-33. doi: 10.22067/jsw.v30i1.45058.

10. Sedki A, Ouazar D. Swarm intelligence for groundwater management optimization. Journal of Hydroinformatics 2011; 13(3): 520-32. doi: 10.2166/hydro.2010.163.

11. Semenov MA, Barrow EM. A stochastic weather generator for use in climate impact studies. [cited 2019 Feb 15] Available from: http://resources.rothamsted.ac.uk/sites/ default/files/groups/mas-models/download/LARS-WGManual.pdf.

12. Hassan Z, Shamsudin S, Harun S. Application of SDSM and LARS-WG for simulating and downscaling of rainfall and temperature. Theor Appl Climatol 2014; 116(1-2): 243-57. doi: 10.1007/s00704-013-0951-8.

13. Wu CL, Chau KW. Rainfall-runoff modeling using artificial neural network coupled with singular spectrum analysis. J Hydrol 2011; 399(3-4): 394-409. doi: 10.1016/j. jhydrol.2011.01.017.

14. Kisi O, Kerem Cigizoglu H. Comparison of different ANN techniques in river flow prediction. Civil Engineering and Environmental Systems 2007; 24(3): 211-31. doi: $10.1080 / 10286600600888565$.

15. Nourani V. An Emotional ANN (EANN) approach to modeling rainfall-runoff process. J Hydrol 2017; 544: 267 77. doi: 10.1016/j.jhydrol.2016.11.033.

16. Tayebiyan A, Ahmad Mohammed T, Ghazali AH, Abdul Malek M, Mashohor S. Potential impacts of climate change on precipitation and temperature at Jor Dam Lake. Pertanika J Sci Technol 2016; 24(1): 213-24.

17. Tayebiyan A, Mohammad Ali TA, Ghazali AH, Malek MA. Future Consequences of Global Warming on Temperature and Precipitation at Ringlet Reservoir, Malaysia. International Conference on Advances in Environment, Agriculture \& Medical Sciences; 2014 Nov 16-17; Kuala Lumpur; 2014.

18. Duku C, Sparks AH, Zwart SJ. Spatial modelling of rice yield losses in Tanzania due to bacterial leaf blight and leaf blast in a changing climate. Clim Change 2016; 135(3-4): 569-83. doi: 10.1007/s10584-015-1580-2.

19. Prescott CL, Dolan AM, Haywood AM, Hunter SJ, Tindall JC. Regional climate and vegetation response to orbital forcing within the mid-Pliocene warm period: a study using HadCM3. Glob Planet Change 2018; 161: 231-43. doi: 10.1016/j.gloplacha.2017.12.015.

20. Tett SF, Yamazaki K, Mineter MJ, Cartis C, Eizenberg N. Calibrating climate models using inverse methods: case studies with HadAM3, HadAM3P and HadCM3. Geosci Model Dev 2017; 10(9): 3567-89. doi: 10.5194/gmd-103567-2017.

21. Dehghan Z, Fathian F, Eslamian S, Adamowski JF. Assessing irrigation network performance based on different climate change and water supply scenarios: a case study in Northern Iran. International Journal of Water 2017; 11(3): 191-208. doi: 10.1504/IJW.2017.085878.

22. Collins M, Tett SF, Cooper C. The internal climate variability of HadCM3, a version of the Hadley Centre coupled model without flux adjustments. Clim Dyn 2001; 17(1): 61-81. doi: $10.1007 / \mathrm{s} 003820000094$.

23. Kisi O, Shiri J, Tombul M. Modeling rainfall-runoff process using soft computing techniques. Comput Geosci 2013; 51: 108-17. doi: 10.1016/j.cageo.2012.07.001.

24. Cilimkovic M. Neural networks and back propagation algorithm. [cited 2019 Feb 11]; Available from: http:// www.dataminingmasters.com/uploads/studentProjects/ 
NeuralNetworks.pdf.

25. Fahlman SE. An empirical study of learning speed in backpropagation networks. [cited 2019 Feb 1]; Available from: https://www.semanticscholar.org/paper/An-empiricalstudy-of-learning-speed-in-networks-Fahlman/00d50ae55 e54d099f9e9d07d507b4bd787abf33a.

26. de Sousa Lima JR, Antonino AC, de Souza ES, Hammecker C, Montenegro SM, de Oliveira Lira CA. Calibration of Hargreaves-Samani equation for estimating reference evapotranspiration in sub-humid region of Brazil. J Water Resour Prot 2013; 5(12A): 1-5. doi: 10.4236/ jwarp.2013.512A001.

27. Tayebiyan A, Ahmad Mohammad T, Ghazali AH, Mashohor S. Artificial neural network for modelling Rainfall-Runoff. Pertanika J Sci Technol 2016; 24(2): 319-30.

28. Samani Z. Discussion of "History and evaluation of Hargreaves evapotranspiration equation" by George $\mathrm{H}$. Hargreaves and Richard G. Allen. Journal of Irrigation and
Drainage Engineering 2004; 130(5): 447-8. doi: 10.1061/ (ASCE)0733-9437(2004)130:5(447.2).

29. Hashmi MZ, Shamseldin AY, Melville BW. Comparison of SDSM and LARS-WG for simulation and downscaling of extreme precipitation events in a watershed. Stoch Environ Res Risk Assess 2011; 25(4): 475-84. doi: 10.1007/s00477010-0416-x.

30. Dlamini NS, Kamal MR, Bin Mohd Soom MA, Faisal Bin Mohd MS, Fikri Bin Abdullah A. Modeling potential impacts of climate change on streamflow using projections of the 5th assessment report for the Bernam River Basin, Malaysia. Water 2017; 9(3): 226. doi: 10.3390/w9030226.

31. Aboutalebi M, Bozorg Haddad O, Loaiciga HA. Optimal monthly reservoir operation rules for hydropower generation derived with SVR-NSGAII. Journal of Water Resources Planning and Management 2015; 141(11): 04015029. doi: 10.1061/(ASCE)WR.1943-5452.0000553. 